\title{
TACTICAL COMBAT CASUALTY CARE: STRATEGIC ISSUES OF A SERIOUS SIMULATION GAME DEVELOPMENT
}

\author{
Hwa Feron \\ Institut für Technische Informatik \\ Werner-Heisenberg-Weg 39 \\ Universität der Bundeswehr München, \\ GERMANY
}

\author{
Marko Hofmann \\ Institut für Technik Intelligenter Systeme \\ Werner-Heisenberg-Weg 39 \\ Universität der Bundeswehr München, \\ GERMANY
}

\begin{abstract}
Serious game techniques permit rapid development of cost effective educational software but face two apparently conflicting objectives: efficiently teaching extremely complex subject matter (such as emergency medical care for a severely wounded, dying casualty) yet enhancing learning motivation by emphasizing game entertainment value. Our development strategy for a battlefield first aid training game for the German Federal Armed Forces resolves this contradiction by relying on separate development teams working in parallel, a pedagogical expert team concentrating on deciding how and in which form the medical principles are to be taught, and a game developer team best able to package that subject-matter in an attractive game with a motivating storyboard and an appealing graphics environment. After an overview of existing battlefield first aid training games and of the essential battlefield first aid procedures to be implemented and simulated, this paper presents concrete elements of our dual-team game development and modeling choices.
\end{abstract}

\section{INTRODUCTION AND MOTIVATION}

U.S. military experience with the principles of Tactical Combat Casualty Care (TCCC) over the past two decades reveals greatly improved battlefield survival rates in case of life-threatening trauma. These principles formalize a series of simple life saving steps and clear priorities to be carried out in the minutes following the injuries and recommend all servicemen, laymen and medics alike, to be familiar with them.

The German Federal Armed Forces (Bundeswehr), realizing that medics cannot be present on every battlefield, has also started to teach these life saving principles not only to its medical personnel, but also to its regular servicemen, with the goal that at least one soldier in every squad should be able and equipped to apply them. However, TCCC training by traditional methods, i.e. with the help of trained instructors, has not been able to adequately meet this ambitious goal, not least because the limited time, budget and limited numbers of competent tutoring personnel are not sufficient for quickly and economically training the required numbers of regular nonmedical personnel without previous first aid skills. In order to alleviate this problem in a cost-effective manner, the "Sanitätsamt" of the Bundeswehr intends to become able to provide the necessary extra training (or at least part of it) by means of a serious game simulating the major aspects of TCCC.

This paper reports on our preliminary studies related to this serious game project, in particular towards providing a game demonstrator laying the foundations for a simulation game capable of teaching most or all TCCC principles to laymen in a fun, engaging and interactive manner.

The paper is organized into two major parts: 


\section{Feron and Hofmann}

- The first section surveys serious gaming, some of its existing applications to battlefield first aid training, TCCC principles, and TCCC casualty modeling strategies for training purposes in the proposed training game.

- The second part discusses the optimal organization of the developer teams as well as our game development strategies in the light of real-world constraints.

\section{GAMES AS COST-EFFECTIVE TRAINING SOLUTION}

Traditional training simulators often require specialized hardware and cost millions to develop and deploy. Using existing infrastructure, game engines and reusing existing videogame code (a.k.a. "game modding"), game developers or ordinary players can create games that simulate battles, processes and events for training purposes at a fraction of the cost of traditional government contractors.

The videogame industry has now matured to a multibillion dollar industry and offers a large pool of trained designers, artists and technologies, as well as low cost hardware on a massive scale, all of which can equally well be used for Serious Games (SGs) purposes. (Seriousgames 2012; Trybus 2010; Smith 2007)

SGs as laptop or smart phone-based training simulators developed by traditional videogame designers also tend to be more engaging than training software designed by traditional defense contractors. Game developers are accustomed to developing games quickly and are experienced at making games fun and motivating as their livelihood depends on them. In the course of simulating events and processes, developers automatically inject entertainment and playability in their applications.

A major challenge of serious games in comparison with regular games is that the algorithms modeling the learning matter have to be validated in the much stronger sense of serious (military) simulations (Kleindorfer, O'Neill, and Ganeshan 1998, Hofmann and Pötzsch 2002). In non-technical applications this is often done by showing subject matter experts typical courses of action in the game (Küppers and Lenhard 2005, Hofmann 2005). Since a playable version of the game is seldom available in the first month of the project, validation has to be postponed to the end of the development. Especially in new application domains this is a dangerous approach because the model is necessarily always an abstraction of reality leading to idealizations which might be critical for the plausibility of the depiction, and also critical with respect to learning effects. Efficient design of a SG may therefore have to begin with the development of a simplified validation interface.

\section{SERIOUS GAMES COTS IN MEDICAL APPLICATIONS}

Table 1 briefly presents a survey of existing SG based on commercial off-the-shelf (COTS) games or game engines for teaching battlefield or multi-trauma first aid:

Table 1: Survey of 3D Serious Games COTS.

\begin{tabular}{|l|l|}
\hline \multicolumn{1}{|c|}{ Application } & \multicolumn{1}{c|}{ Description } \\
\hline $\begin{array}{l}\text { Tactical Combat Casualty Care Simu- } \\
\text { lation (TC3 Sim 2009) }\end{array}$ & $\begin{array}{l}\text { Army Combat Medic and Combat Lifesavers Training under } \\
\text { battlefield conditions. }\end{array}$ \\
\hline $\begin{array}{l}\text { Combat Lifesaver Mobile Medic Ap- } \\
\text { plication (TraumaCon 2012) }\end{array}$ & $\begin{array}{l}\text { Two 2D mobile training games with multiple choice ques- } \\
\text { tions based on the CLS course material. }\end{array}$ \\
\hline $\begin{array}{l}\text { Computer Based Corpsmen Training } \\
\text { System TM (CBCTS 2009) }\end{array}$ & $\begin{array}{l}\text { Improvement of TC3 Sim (TC3 Sim 2009) for training Com- } \\
\text { bat Medic. }\end{array}$ \\
\hline $\begin{array}{l}\text { Interactive Trauma Trainer (ITT) } \\
\text { (Stone 2006; TruSim 2006) }\end{array}$ & $\begin{array}{l}\text { Interactive treatment of battlefield casualties from battlefield } \\
\text { to hospital (SG Engine: BlitzTech). }\end{array}$ \\
\hline $\begin{array}{l}\text { Sim-Patient TM } \\
\text { (SimPatient 2012; Kizakevich 2006) }\end{array}$ & $\begin{array}{l}\text { Interactive 3-D avatars of patients with simulated physiologi- } \\
\text { cal responses to train medical providers on pre-hospital care. }\end{array}$ \\
\hline $\begin{array}{l}\text { Emergency Preparedness Training } \\
\text { (CBRNE 2010; Magee 2010) }\end{array}$ & $\begin{array}{l}\text { Multiplayer virtual emergency room for Chemical, Biologi- } \\
\text { cal, Radiological, Nuclear Event (CBRNE) mass casualties. }\end{array}$ \\
\hline
\end{tabular}




\begin{tabular}{|l|l|}
\hline $\begin{array}{l}\text { Code Orange TM Emergency Medical } \\
\text { Management Training for Mass Catas- } \\
\text { trophe (Code Orange 2012) }\end{array}$ & $\begin{array}{l}\text { Multiplayer catastrophic events training for emergency medi- } \\
\text { cal teams (SG Engine: Mosbe). }\end{array}$ \\
\hline Pulse !! (Pulse 2008; McDonald 2011) & $\begin{array}{l}\text { Simulation of different pathologies, patients, settings and } \\
\text { emergencies in a virtual environment (SG Engine: Mosbe). }\end{array}$ \\
\hline HumanSim TM (HumanSim 2011) & $\begin{array}{l}\text { Healthcare training for Physicians and nurses, Emergency } \\
\text { medical personnel (SG Engine: Unreal Engine 3). }\end{array}$ \\
\hline
\end{tabular}

\section{A SIMULATION- / GAME-BASED MEDICAL TRAINING FOR COMBATANTS}

Our SG demonstrator, based on the lessons learned from the above survey of existing 3D SG COTS, is intended to be mostly scenario-driven (scripted) and to teach multiple players Operational Field Care First Aid Measures for various injuries/trauma in combat situations. The target users are Combatants/First Responders i.e. initial providers of life saving care.

Since the Bundeswehr bases its training on Tactical Combat Casualty Care Guidelines (Josse 2008), the serious game to be designed must implement training according to TCCC.

TCCC originated from the 1993 experience of US special operations forces in Mogadishu, Somalia, and is based on the realization that priority emergency treatment on the battlefield of treatable exsanguination and breathing injuries, previously representing $15 \%$ of all Killed in Action (KIA) can save those lives (see Table 2) (Butler 2007, TCCC Intro 2010). TCCC has since been expanded to include first aid treatment to other life threatening injuries (e.g. burns, hypothermia), but still gives top priority to these injuries.

Table 2: Cause of preventable KIA and TCCC Skills.

\begin{tabular}{|l|l|l|}
\hline KIA & Causes of KIA & TCCC Teaching Medical Skills \\
\hline $9 \%$ & $\begin{array}{l}\text { Hemorrhage from Extremity } \\
\text { Wounds }\end{array}$ & $\begin{array}{l}\text { Hemorrhage control through the use of the } \\
\text { new field Tourniquets }\end{array}$ \\
\hline $5 \%$ & Tension Pneumothorax (PTX) & Treatment of Tension Pneumothorax \\
\hline $1 \%$ & Airway Problems & Airway Management \\
\hline
\end{tabular}

The first aid TCCC procedures to be taught are detailed in the following references:

- Prehospital Trauma Life Support (PHTLS) from PHTLS Committee of the National Association of Emergency Medical Technicians (NAEMT) in cooperation with the American College Surgeons Committee on Trauma, Military Edition, English version (PHTLS 2010); abridged German version (PT PHTLS 2011). The PHTLS manual is revised every 4 years and includes the latest version of TCCC Guidelines.

- TCCC-Guidelines; -Skills List; -Scenario from US DOD Military Health System (TCCC Guidelines 2010; TCCC Skills List 2010); German version, slightly adapted to special German procedures and needs (“Taktische Verwundetenversorgung”) published by TREMA e.V. (TREMA 2010).

\subsection{Three Phases of Tactical Combat Casualty Care}

TCCC is based on the overriding time management principle of performing the correct intervention at the correct time in the continuum of field care. Accordingly, its procedures are optimized and structured to meet three important goals: (1) treat the casualties needing immediate care, (2) prevent additional casualties, and (3) complete the mission. To meet them in a combat environment, the TCCC principles are formulated as a simple algorithm comprising three successive phases: Care under Fire, Tactical Field Care, and Combat Casualty Evacuation Care. 


\section{Feron and Hofmann}

The Care under Fire (CUF) phase covers approx. the first 5 minutes after the time the casualty has been injured; during this period the main priorities are not medical (except stopping life-threatening hemorrhages e.g. by use of a tourniquet and/or hemostatic dressing) but rather suppression of hostile fire and moving the casualty to a safer location: most medical treatment is delayed to the next phase.

The Tactical Field Care (TFC) phase is meant for the fellow combatants to provide the actual emergency medical care to the casualties following the end of the CUF phase and prior to evacuation (typically a few minutes to a few hours), after a relative protection from enemy fire has been achieved. Care is provided only to casualties needing Immediate attention (and not to casualties in the Expectant, Delayed or Minimal triage categories, see Section 4.3) and is provided strictly according to the priority order X-A-BC-D-E (see Figure 1 for details). In TFC it is almost as important to provide documentation for the next level of casualty care, for instance directly on the skin of the casualty (e.g. indication of tourniquet) and by recording injuries, emergency treatments and vital signs on the Tactical Combat Casualty Care Card (e.g. DA Form 7656).

The Combat Casualty Evacuation Care (CASEVAC or MEDEVAC) phase refers to the time period dedicated to evacuation of combat casualties from the battlefield, e.g. removal from a vehicle and transportation to the appropriate evacuation vehicle e.g. using Fireman's carry or Improvised litter, while providing the desirable level of care during transportation to the higher echelon of care.

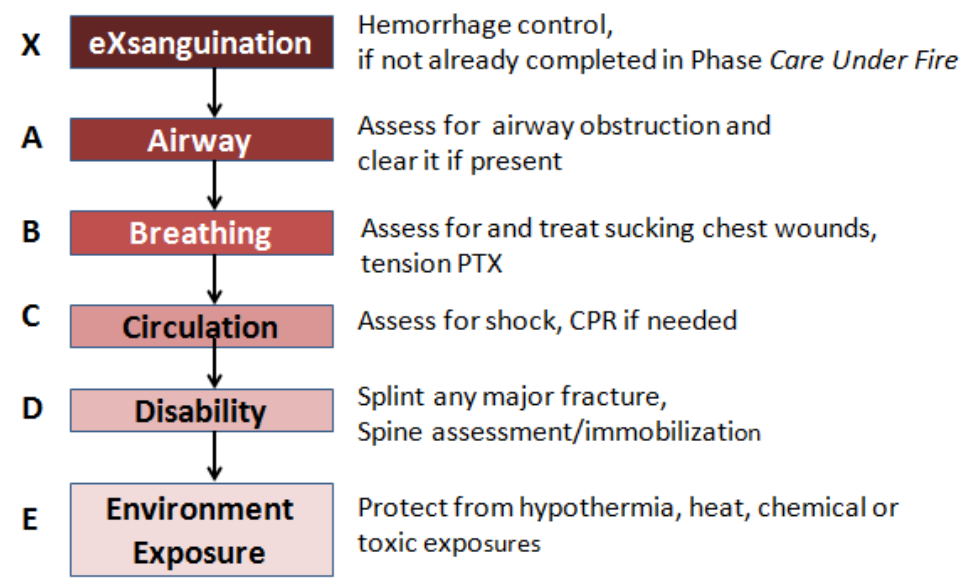

Figure 1: X-A-B-C-D-E first aid priority procedure (PHTLS 2010)

\subsection{Triage in Tactical Combat Casualty Care}

Triage is the process of sorting or prioritizing casualties into groups based on their need for, or likely benefit from, immediate medical treatment so as to establish an order of treatment or movement (PHTLS 10). Effective triage may dictate that some do not receive treatment based on their probabilities of survival.

There are four triage categories: Minimal, Expectant, Delayed, and Immediate. Those in the Minimal (walking wounded) and Expectant (extremely severe, untreatable injuries leading to unpreventable death) categories will receive no treatment; those in the Delayed category will have to wait; the whole purpose of TCCC is to save the life of those casualties in the Immediate category.

\subsection{Battlefield Injuries/Trauma according to TCCC/PHTLS Military Edition}

Table 3 presents a general introduction to the types of injuries which should be foreseen for first responder training in TCCC serious game scenarios: the game logic should therefore provide for simulation of the symptoms, vital signs evolution and treatment of these particular injuries. 
Table 3: Battlefield Injuries/Trauma.

\begin{tabular}{|l|l|l|}
\hline Injury & $\begin{array}{l}\text { Vital signs evolution } \\
\text { and modeling }\end{array}$ & Treatment \\
\hline Exsanguination (Hemorrhage) & Fast, model required & Tourniquet, Pressure, Hemostatic dressings \\
\hline Airway Obstruction & Fast, model required & $\begin{array}{l}\text { Special maneuvers or position, Special airway } \\
\text { tubes, e.g. Nasopharyngeal airway (NPA) }\end{array}$ \\
\hline Breathing (Tension PTX) & Fast, model required & Needle thoracostomy, Chest wound dressings \\
\hline Hypothermia/Exposure & Slow, scripted & Survival blankets, Rewarming \\
\hline Eye Penetrating Trauma & Slow, scripted & Eye shields \\
\hline Blast Trauma & According to injuries & According to scripted individual injuries \\
\hline Burn Injuries & Slow, scripted & $\begin{array}{l}\text { Appropriate bandage and intravenous (IV) ac- } \\
\text { cording to Rule of Nines, Survival blanket }\end{array}$ \\
\hline Psychological Trauma & Slow, scripted & Taking away all weapons and possible isolation \\
\hline
\end{tabular}

\section{DESIRABLE SERIOUS GAME LOGIC FOR TCCC APPLICATIONS}

Since TCCC concentrates on only certain kinds of injuries, training should be provided to deal specifically with those injuries: this requires a heavily scripted game scenario, in which the sustained injuries and their detailed characteristics and symptoms are actually predefined by the scenario and not just occurring by chance or at random.

The trainee is supposed to respond to these injuries by applying his knowledge. How timely he will respond, and with which treatment options cannot be foreseen a priori. The outcome on the survival of the casualty may be gravely affected, even within minutes, by the timeliness and correctness of the decisions of the trainee, in particular for those injuries causing exsanguination or blood oxygen depletion.

For those specific injuries (hemorrhage, breathing impairment) which may have irreversible consequences within minutes in case the correct first aid actions are delayed, a purely scripted response is strongly believed not to be appropriate: instead, a realistic simulation and versatile modeling of the rapid evolution of the physiology and vital signs of the casualty is needed, if only to aid diagnosis.

By contrast, for those life threatening injuries for which the appropriate response is unique and/or less time-critical, more limited in effectiveness or for which the symptoms are more immediately visible (hypothermia, severe burns, penetrating eye trauma or mental status), then a scripted assessment of the validity and effects of the response seems to lead to a more economical and more appropriate implementation in a serious game intended to support TCCC training.

According to Garris, Ahlers, and Driskell (2002) cited by Sotomayor (2008), the learning effectiveness of the games is decisively increased by debriefing: a review and analysis of events and players actions which occurred in the game itself, allowing the participant to draw parallels between game events and real-world events to understand how well his performance met the game's training objectives and actually learn from his mistakes. Such a debriefing can be either built in the software or can be implemented as a trainer/trainee discussion, but it should not be omitted, or else much of the training experience may be lost.

\section{GAME DEVELOPMENT STRATEGY AND TEAM COOPERATION}

The basic philosophy of SGs is to keep costs down by reusing existing game technologies, still keeping in mind the special needs of SGs (reliable teaching, debriefing and review etc.). The greatest reduction in game development costs is obtained by reusing game engines, game characters and game worlds which have been made available, sometimes for free, to the user community, to allow game modding. For instance, the website Mod DB (2012) lists over 300 such engines and many user-developed game mods, which are often reusable in whole or in part, especially in aspects of the following technologies, for game modification purposes. 


\section{Feron and Hofmann}

The TCCC training game must meet contradictory development challenges:

- It must be "serious", i.e. the "core processes of TCCC" must be implemented with sufficient medical accuracy to provide valid and useful training (realistic depiction of weapon effects, wounds, treatments and effects of treatments)

- Its "game" aspects must motivate and promote learning by being as immersive and as much fun as possible, to encourage the trainees to voluntarily play, and learn by playing, as often as possible, ideally also in their leisure time.

\subsection{Dual Team Development Strategy and Team Independence}

Medical or simulation experts are not 3D game engine experts nor game graphic artists, moreover, the whole idea of "serious games" is to save development time and funding by reusing the game world, developer expertise and graphics engine of an existing game. Therefore this "fun gaming" challenge is being met through a partnership with a reputable game developer team with particular expertise in first aid game storyboards.

Due to its many years of past experience with the development of the commercial "Emergency" computer game (Emergency-Game 2012) and some experience with a SG for disaster medicine (VoTekkSimulation 2012), the game developer team "Serious Games Solutions GmbH" of Potsdam, Germany, met our partnership expectations. Its existing game world (see Figure 2) is already able to represent various civilian first aid situations and is believed to require only little modification to accommodate the military graphical environment desired by the Bundeswehr. This professional game developer team will therefore be in charge of implementing the few missing aspects of the $3 \mathrm{D}$ game engine and graphical environment (additional landscapes, training scenarios, military vehicles, weapons and weapon effects, uniforms, interfaces) needed for a battlefield environment. However, it does not have the required medical and simulation expertise for implementing and validating the medical aspects of TCCC on casualties models.

Since TCCC deals with time-critical life-and-death situations, the conceptual design and prototypical development model for the core medical processes required for proper modeling of casualty symptoms and activities must be thoroughly validated, i.e. shown to be "highly plausible for medical experts" (many lives may be at stake if the training software is inadequate in any way). Our team of simulation experts (ITIS GmbH, UniBw) seconded by Red Cross medical personnel, intends to perform this validation in parallel with the modification of the 3D game by our game developer partners.

The future, "Emergency professional" version of our partners 3D game, introducing the desired "egoshooter perspective" as well as an additional "casualty perspective" is still under development: as the validation of the medical models cannot be postponed until that version becomes playable, a simple, temporary, low-tech (2D) java game interface has been foreseen (see 2D interface screenshots on Figure 4). It is only intended for quick modeling and medical interface prototyping by the simulation team as well as for proper testing and validation of the medical aspects throughout development; it furthermore allows both teams to efficiently conduct most of the development work in parallel without excessive interference.

Details of the scenario, the level design, 3D-graphics and many other necessary aspects of an engaging and professional game are fully disregarded in this simplified game interface because these tasks are part of the mission of our game developer partner team. After user interface development, plausibility testing, physiological validation and practical testing of the TCCC casualty model on this simplified interface, the core casualty model and the player interface will be transferred to their final 3D serious game environment, which will be implemented as a military modification of the rescue services computer game of our game developer partners. Until then, the 2D-demonstrator, consisting of the casualty model, the player input interface, and the 2D graphics interface, see Figure 4, will be the platform for assessing the quality of the core processes. 


\section{Feron and Hofmann}

We therefore took the major strategic decision to separate the first phases of the project into two parts carried out by two distinct teams. The $2 \mathrm{D}$ validation interface which enabled the teams to efficiently conduct their development work in parallel also substantially simplifies the organization of the project, and is expected to reduce its projected time duration. Furthermore, it allowed us to select simply the best available talent for this type of game, since the work of the two teams can be substantially decoupled without restrictions of time and place: they need a close cooperation only towards the end of the project.

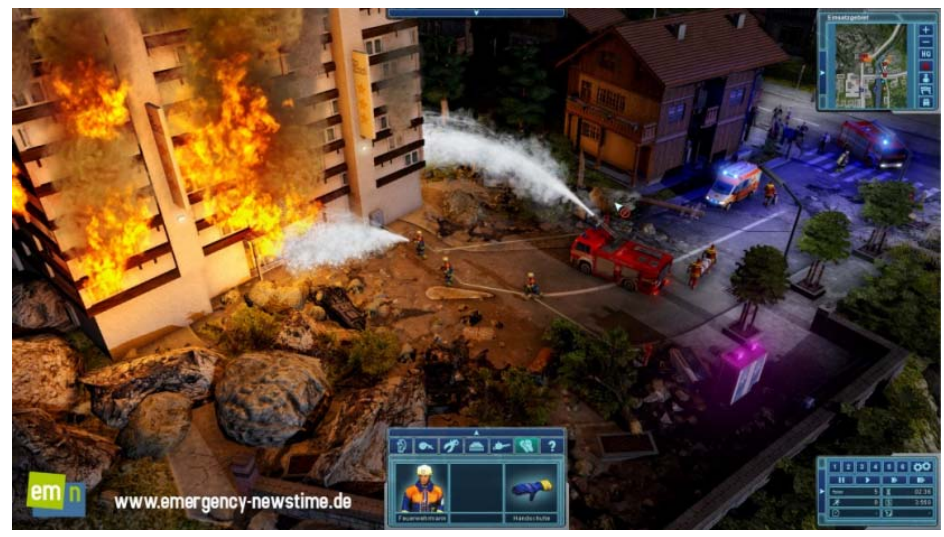

Figure 2: Screenshot from the current version of the commercial game "Emergency"

\subsection{Details, Role and Implementation of the temporary 2D Game Interface}

The simplified demonstrator is a crucial part of the overall project, and is the result of the work of the simulation team alone. It combines the TCCC simulators and user input interface with the abovementioned 2D validation interface, and implements all processes (i.e. core processes) contributing directly to the learning matter of TCCC.

The core processes of TCCC to be implemented are:

- TCCC-relevant trauma and their evolution (see Table 3),

- treatments of these trauma according to TCCC,

- effects of TCCC treatments and erroneous treatments on the evolution of the vital functions, and

- essential tactical, terrain and environment aspects, e.g. self protection and weather.

The evolution of the vital signs caused by trauma is modeled in a plausible manner by using an appropriate casualty model for each injury type. These models (e.g. a hemorrhage model and a oxyhaemoglobin saturation model able to simulate lung function, pneumothorax and airway obstruction effects on blood oxygen) attempt to generate a plausible trauma-dependent, time-dependent and treatmentdependent variation of all measurable vital signs, e.g. in case of severe blood loss, burns, breathing problems, etc.

For instance, the simplified hemorrhage simulation model based on fundamental principles of hemodynamics (Milnor 1989) as schematically represented in Figure 3 (in which the lungs are not explicitly represented since their function is represented by another model) would attempt to set the evolution of vital signs as a function of the vital parameter "overall blood volume" based on clinical data (similar, systemic hemodynamics models are described in Levy 1979; Greenway 1980; Doherty 1993; a comprehensive theory is provided by Sramek 2002, 2009). Due to its severe abstraction from reality (sketched on the left side of Figure 3) the adequacy of such a model (the right side of Figure 3) can only be assessed by medical experts via a visualization of its effects in the demonstrator.

In this simulation, which is solely intended to mimic the blood loss rates for a variety of injuries, and in which blood circulation in and through different body parts is represented by rectangles in which blood 


\section{Feron and Hofmann}

loss at a certain rate can be represented by a bucket symbol collecting spilt blood, the overall blood volume is derived e.g. by integrating the blood loss over time. A crude tourniquet effect simulation is obtained by closing off links between the appropriate rectangles.

The blood loss through a given blood vessel wound can either be calculated via the Bernouilli equation (Klabunde 2011) for uncompressible fluids in pipes, modeled by a fluid flow resistance or can be preset to an experimentally known value for a given artery diameter, knowing that volumetric flow rate is roughly proportional to the square of the diameter of the artery.
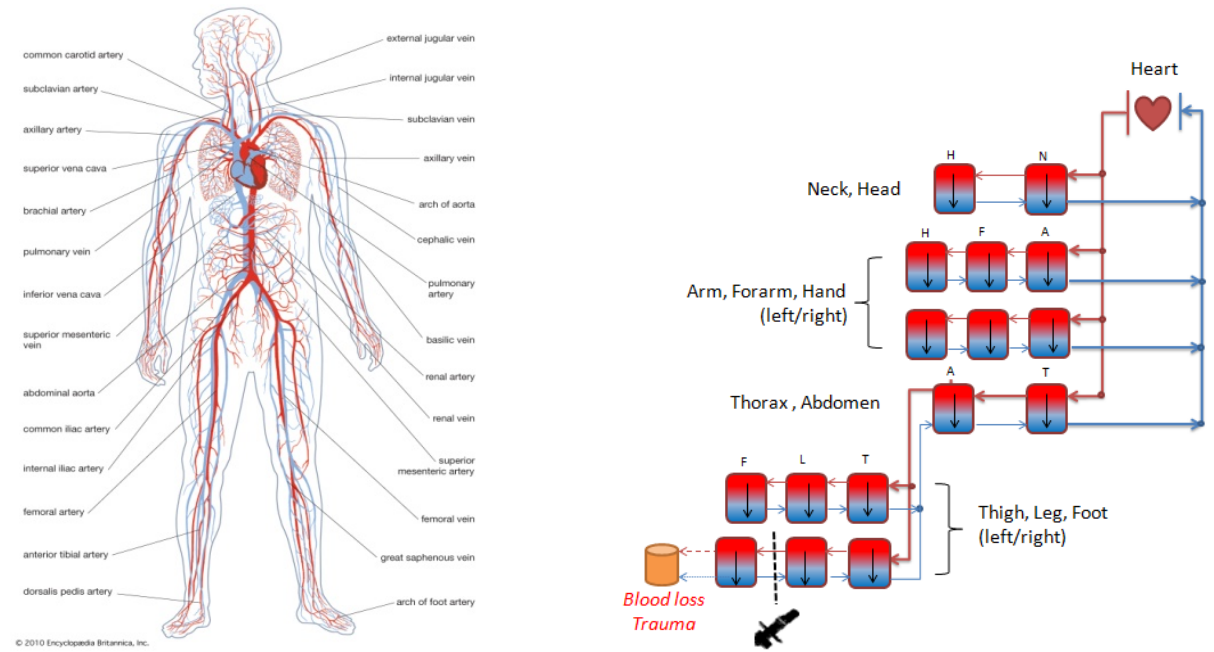

Figure 3: "Realistic" depiction of human blood vessels (Britannica 2010) (left) versus a simplified hemorrhage model (right), represented in the case of a hemorrhagic foot trauma with tourniquet application
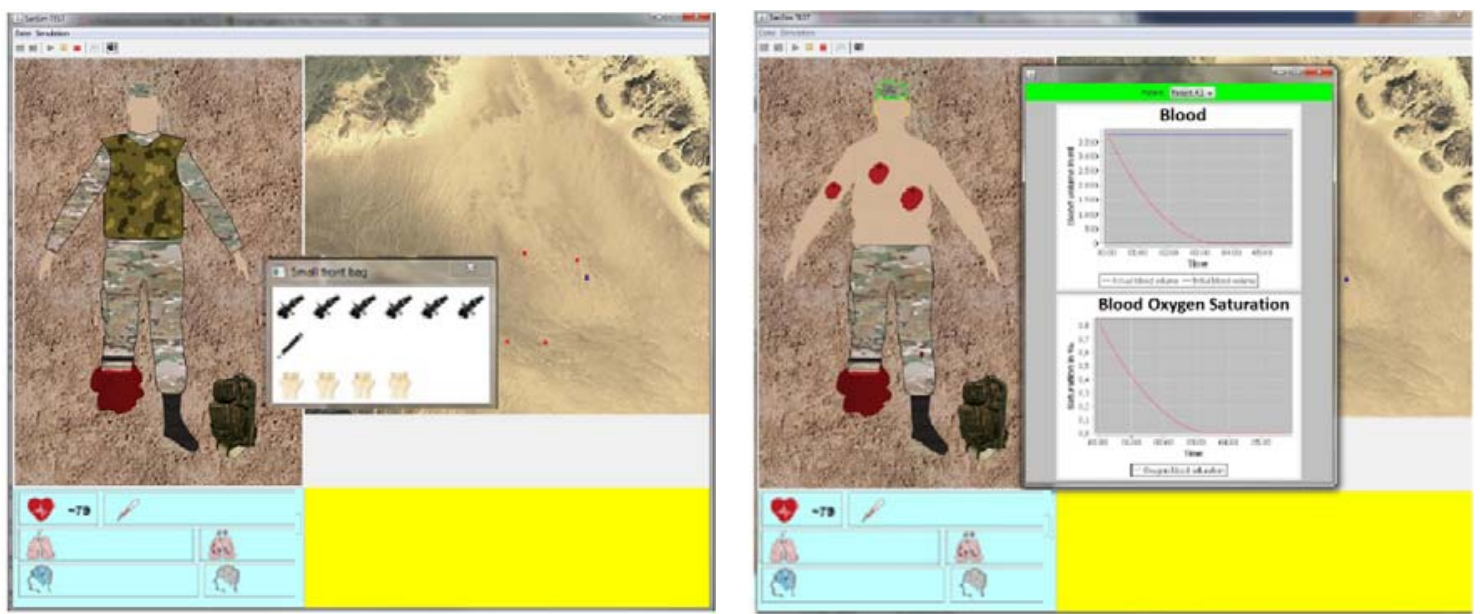

Figure 4: Screenshots of the 2D-Demonstrator with selected vital parameters display (right)

The demonstrator interface (Figure 4) is composed of a simplified tactical overview (top right), the casualty under examination and treatment (top left), the tools available for treatment (the center window pops-up by clicking on the medic's knapsack symbol), vital signs like pulse and temperature (bottom left), and a window for other purposes like multi-player modus (bottom right). In a special pop-up window selected vital parameters can be visualized (Figure 4, right). 


\section{Feron and Hofmann}

\subsection{Casualty Vital Signs Simulation}

According to the TCCC algorithm (see e.g. Figure 1), vital signs are the basis on which any combat life saver (layman or expert) has to ground its treatments. Depending on experience, measurement tools and available time, the number of observable vital signs might be very restricted and the signs themselves may be misjudged, however they are the only way to obtain clues about vital functions, e.g. brain function and important but inherently non-measurable vital parameters like blood volume. In the real world, these vital signs can be directly observed or measured with additional devices, e.g. pulse oximeter. The most commonly used vital signs are: pulse rate, blood loss, state of consciousness, respiration rate, blood pressure and body temperature.

During discussion with medics, and, in particular, with experts from the Red Cross it has become clear that they expect certain vital signs variations in the case of certain trauma. For this reason, the first steps of simulation, representation and validation have been focused on plausible evolution of vital signs for these trauma, as they are at least as important for diagnosis and teaching purposes as a valid and physiologically correct modeling of the vital parameters.

\section{CONCLUSION}

The long list of examples of existing medical training games show that immersive simulation-based learning in the form of serious games has received a lot of attention and has generally become well accepted, particularly for training decision-making skills such as Emergency Medical Services (EMS) battlefield training. Since several competing products are available, it should be possible to study the training strategies which work best, so that more effective serious games based medical training products can now be developed to cost-effectively address every specialised need.

After surveying the TCCC rescue and treatment strategies which must be taught and implemented in a realistic serious game for military and medical training, we gained more insight on the ways in which the casualty and its environment must be modelled. We then elected to develop and validate a casualty model consisting of several physiological injury submodels for generating plausible vital signs in response to injuries and treatment actions in a temporary $2 \mathrm{D}$ validation interface, which permits a parallel development of the medical modelling and of the 3D environment of the game by separate teams. After validation, the TCCC models will be integrated in a 3D first person shooter environment by way of game modding of an existing first aid computer game of our game developer partners.

We believe that effective serious games have to present an elusive mixture of didactic seriousness for effective learning and gaming fun for increasing motivation and interest, thus requiring an effective cooperation of subject-matter experts, didactic experts, simulation experts and game developers (in their multiple roles of game programmers, sound and graphic artists, computer graphics experts, gamer psychologists and game ergonomy experts). However, many of these experts have different priorities which may be hard to reconcile in a single team. Indispensable discussions about the intricacies and interdependencies of TCCC details, adequate learning procedures and necessary abstraction levels are daunting and of little value for game developers, whereas the inner working of game engines is far beyond the level of understanding even for regular simulation experts, not to speak of pedagogic experts or medics. The latter would make bad game designers, and the former would quickly become impatient with medical, validation or pedagogic aspects: the clean division of work enabled by the temporary $2 \mathrm{D}$ validation interface saved a lot of time and frustration on both sides, and did not generate inefficiencies so far.

Although designing a temporary simplified 2D validation interface has been a burden, we believe it has brought us some significant advantages:

First, this interface allows each team to concentrate on what they do best, with minimal interference from the other: the outcome should be a better teaching tool and a more engaging game. Second, the simplified $2 \mathrm{D}$ validation interface allows both teams to work in parallel: validation could start over a year earlier, even though aspects of the 3D commercial game which otherwise would have been necessary for valida- 


\section{Feron and Hofmann}

tion of the models are still under development. Because of this parallelism without interference or frustration, the work is estimated to progress much faster.

\section{ACKNOWLEDGEMENTS}

The authors wish to thank the Sanitätsamt der Bundeswehr (esp. Dr. L. Schneidereit) for funding this research, as well as the project contributors and partners, such as the Deutsches Rotes Kreuz Landesschule Baden-Württenberg e.V. (esp. Mr. R. Kuhnke), Serious Games Solutions GmbH (esp. Mr. R. Stock), our Institut für Technik Intelligenter Systeme GmbH and the Universität der Bundeswehr colleagues (esp. Prof. Dr. Axel Lehmann), together with several individuals who are too numerous to name separately, for their help and their valuable contributions.

\section{REFERENCES}

Bonk, J., and P. Dennen. 2005. "Massive Multiplayer Online Gaming: A Research Framework for Military Education and Training." Technical Report 2005-1. Office of the Under Secretary of Defense (Personnel and Readiness), Readiness and Training Directorate, Advanced Distributed Learning (ADL) Initiative, Washington D.C.

Britannica 2010. "Human Circulatory System.” Encyclopaedia Britannica Online. Accessed July 1, 2012. http://www.britannica.com/EBchecked/media/141810/Human-circulatory-system.

Butler 2007. Butler, Frank K. "Tactical Combat Casualty Care 2007: Evolving Concepts and Battlefield Experience." Military Medicine, Vol. 172, 11:1.

CBCTS 2009. "Computer Based Corpsmen Training System TM." Engineering \& Computer Simulations, Inc., Orlando, Florida. Accessed March 12, 2012. http://www.ecsorl.com/.

CBRNE 2010. "OLIVE - Medical Simulation Training for Chemical, Biological, Radiological, Nuclear Event (CBRNE) Training." Science Applications International Corp., McLean, Virginia. Accessed March 11, 2012. http://media.saic.com/videos/olive-3d-emergency-preparedness-training.

Code Orange 2010. "Code Orange ${ }^{\mathrm{TM}}$ - Emergency Medical Management Training for Mass Catastrophe." BreakAway Ltd., Cockeysville, Maryland. Accessed March 12, 2012. http://www.breakawaygames.com/serious-games/solutions/homeland/.

Doherty T.J. 1993. "A mathematical model of the circulation for the study of hemorrhagic shock and fluid resuscitation: the isolated left heart." Institute Report 479, Letterman Army Institute of Research, Presidio of San Francisco, CA.

Emergency-Game 2012. Published by Deep Silver, a division of Koch Media GmbH, with cooperation by Serious Games Solutions GmbH, Potsdam, Germany. Accessed March 20, 2012. http://e2012.deepsilver.com/.

Garris, R., R. Ahlers, and J. Driskell. 2002. "Games, Motivation, and Learning: A Research and Practice Model.” In Simulation \& Gaming, Vol. 33 No. 4: 441-467. DOI: 10.1177/1046878102238607. SAGE Publications, Inc.

Greenway C.V. 1980. "Simple model of the circulation." Physiologist 23: 63-67.

Hofmann, M. 2005. „Epistemologische Grenzen der klassischen Validierung bei komplexen Simulationsmodellen." Proceedings of the 18th Symposium on Simulationstechnique. Erlangen, Germany.

Hofmann, M., and Pötzsch, V. 2002. „Validation: Possibilities and Limits in High Resolution Combat Simulation Systems." In Proceedings of 2002 the 1. European Simulation Interoperability Workshop. Harrow, UK.

HumanSim 2011. "HumanSim ${ }^{\mathrm{TM}}$." Applied Research Associates Virtual Heroes Division, Raleigh, North Carolina. Accessed March 12, 2012. http://www.virtualheroes.com/healthcare.asp.

ITT 2006. "Interactive Trauma Trainer." TruSim, Blitz Game Studios Ltd., Warwickshire, UK. Accessed March 12, 2012. http://www.trusim.com/. 


\section{Feron and Hofmann}

Josse, F. 2008. "Sanitätsausbildung für Spezial- und Spezialisierte Kräfte.“ In Wehrmedizin und Wehrpharmazie. 2/2008. Accessed March 12, 2012. http://www.wehrmed.de/article/1131Sanitaetsausbildung fuer Spezial- und spezialisierte Kraefte.html.

Kizakevich, P., R. Furberg, R. Hubal and F. Frank. 2006. "Virtual Reality Simulation for Multicasualty Triage Training." In Proceedings of the 2006 Interservice/Industry Training, Simulation, and Eduction Conference (I/ITSEC). Orlando, Florida.

Klabunde, R. 2011. "Cardiovascular Physiology Concepts." Lippincott Williams \& Wilkins, Pennsylvania. (Bernoulli Model: http://www.cvphysiology.com/hemodynamics/H012.htm.).

Kleindorfer, G. B., L. O'Neill, and R. Ganeshan. 1998. "Validation in Simulation: Various Positions in the Philosophy of Science." Management Science, 44(8):1087-1099.

Küppers, G., and J. Lenhard. 2005. "Validation of simulation: Pattern in the social and natural sciences." Journal of Artificial Societies and Social Simulation (JASSS). 8(4).

Levy, M.N. 1979. "The Cardiac and Vascular Factors That Determine Systemic Blood Flow." Circulation Research 44:739-746.

Magee, H. 2010. "A New Era in Medical Training through Simulation-Based Training Systems." RTOMP-HFM-182-11. Use of Advanced Technologies and New Procedures in Medical Field Operations: RTO-MP-HFM-182. NATO Research and Technology Organisation.

Marks, S., J. Windsor, and B. Wünsche. 2008. "Evaluation of Game Engines for Simulated Clinical Training." In Proceedings of the 2008 New Zealand Computer Science Research Student Conference (NZCSRSC). Christchurch, New Zealand.

McDonald, C.L. 2011. "Pulse!! The Virtual Clinical Learning Lab and Center of Excellence." Office of Naval Research in cooperation with Texas A\&M University. Corpus Christi, Texas. Technical Report. Award Number: N00014-10-1-0203. Arlington, Virginia. http://www.dtic.mil/dtic/tr/fulltext/u2/a549718.pdf. [Accessed March 15, 2012].

Milnor, W. 1989. "Hemodynamics." Williams \& Wilkins. Baltimore, Maryland.

Mod DB 2012. "Games and mod development for Windows, Linux and Mac - Mod DB.” Desural NET Pty Ltd., Melvourne, Australia. Accessed March 15, 2012. http://www.moddb.com/.

Petridis, P., I. Dunwell, S. de Freitas, and D. Pantoli. 2010. "An Engine Selection Methodology for High Fidelity Serious Games." In Proceedings of the 2010 Second International Conference on Games and Virtual Worlds for Serious Applications (IEEE VS-GAMES). Braga, Portugal.

PHTLS 2010. "PHTLS: Prehospital Trauma Life Support." Military $7^{\text {th }}$ Edition. NAEMT. Mosby/JEMS.

PT PHTLS 2011. „Präklinisches Traumamanagement: Prehospital Trauma Life Support (PHTLS). “ Urban \& Fischer Verlag/Elsevier GmbH.

Pulse 2008. "Pulse !! ." Virtual Clinical Learning Lab. BreakAway Ltd., Hunt Valley, Maryland. http://www.mosbe.com/downloads/medical_curriculum_final.pdf. [Accessed March 12, 2012].

SeriousGames 2012. „The Serious Games Initiative.“ Woodrow Wilson International Center for Scholars, Washington D.C. Accessed March 12, 2012. http://www.seriousgames.org/about2.html.

Sim-Patient 2012. "Sim-Patient ${ }^{\mathrm{TM}}$." Research Triangle Institute (RTI), Durham, North Carolina. Accessed March 12, 2012. http://www.rti.org/page.cfm/SimPatient.

Smith, R. 2008. "Five Forces of Game Technology Adoption." In Proceedings of the 2008 Interservice/Industry Training, Simulation, and Education Conference (I/ITSEC). Orlando, Florida.

Sotomayor, T. 2008. "Evaluating Tactical Combat Casualty Care Training Treatments Efects on Combat Medic Trainees in Light of Select Human Descriptive Characteristics." Ph.D. dissertation, College of Engineering and Computer Science, University of Central Florida, Orlando, Florida. http://etd.fcla.edu/CF/CFE0002396/Sotomayor_Teresita_M_200812_PhD.pdf. [Accessed March 22, 2012].

Sramek, B. Bo. 2002. "Systemic Hemodynamics and Hemodynamic Management." Instantpublisher.com, Collierville, Tennessee. Accessed March 12, 2012. http://bomed.us/hembook.html.

Sramek, B. Bo. 2009. "Systemic Hemodynamics and Hemodynamic and Oxygen Transport Management." Accessed March 30, 2012. http://www.hemodynamicsociety.org/syshemo.html. 


\section{Feron and Hofmann}

Stone, R. 2006. “Applications in Defense." Defense Management Journal. Education and Training. Issue 32. Publicservice.co.uk Ltd., Staffordshire, UK.

TC3Sim 2009. "Tactical Combat Casualty Care Simulation.” Engineering \& Computer Simulations, Inc., Orlando, Florida. Accessed March 12, 2012. http://www.ecsorl.com/solutions/products/tc3/.

TCCC Intro 2010. "Introduction to TCCC." Military Health System, U.S. Department of Defense. http://mhs.osd.mil/Libraries/101101_TCCC_Course_Materials/0203PP01_Introduction_to_TCCC_10 1101.pptx. [Accessed March 12, 2012].

TCCC Guidelines 2010. “TCCC Guidelines.” Military Health System, U.S. Department of Defense. http://www.health.mil/Libraries/101101_TCCC_Course_Materials/TCCC_Guidelines_101101.pdf. [Accessed March 12, 2012].

TCCC Scenario 2010 “TCCC Scenario.” Military Health System, U.S. Department of Defense. http://www.health.mil/Libraries/101101_TCCC_Course_Materials/020405_TCCC_Scenarios_IG_10 1101.pdf. [Accessed March 12, 2012].

TCCC Skills List 2010. “TCCC Skills List.” Military Health System, U.S. Department of Defense. http://www.health.mil/Libraries/101101_TCCC_Course_Materials/0301_TCCC_Skill_Sets_by_Provi der_Level_101101.pdf. [Accessed March 12, 2012].

TraumaCon 2010. "TraumaCon TM/ Combat Lifesaver MMA." Engineering \& Computer Simulations, Inc., Orlando, Florida. Accessed March 12, 2012. http://www.ecsorl.com/solutions/products/mobileapplications/combat-lifesaver-mma/.

TREMA 2010. „Richtlinien der TREMA e.V. für TCCC (Taktischen Verwundetenversorgung).“ V.1.1. Tactical Rescue \& Emergency Medicine Association e.V. Ulm, Germany. http://www.tremaonline.info/TREMA\%20e.V.\%20Guidelines\%20TCCC\%201.1.pdf. [Accessed March 12, 2012].

Trybus, J. 2010. "Game-Based Learning: What it is, Why it Works, and Where it's Going." NMI White Paper. New Media Institute, New York, New York. Accessed March 14, 2012. http://www.newmedia.org/game-based-learning--what-it-is-why-it-works-and-where-its-going.html.

Votekk-Simulation 2011. BMBF-Verbundprojekt VoTeKK, Deutsches Institut für Katastrophenmedizin $\mathrm{GmbH}$, with cooperation from Serious Games Solutions GmbH, Potsdam, Germany. http://www.seriousgames-berlin.de/archiv/2011/august/votekk-notarzttrainer.html.

\section{AUTHOR BIOGRAPHIES}

HWA FERON is a researcher at the University of the Federal Armed Forces Munich, Germany. After professional experience with health insurance databases at Blue Cross/Blue Shield of Western Pennsylvania and organ transplant databases at the Regional Organ and Tissue Bank, Rush-Presbyterian Hospital, Chicago, she obtained a M.S. in artificial intelligence at Illinois Institute of Technology, Chicago.

Her e-mail address is hwa.feron@unibw.de.

MARKO HOFMANN has studied computer science in Munich. He is a project manager at the Institute for Technology of Intelligent Systems and a lecturer at the University of the Federal Armed Forces Munich, Germany. He has written his dissertation (2000) and "habilitation" (2010) on military computer simulation. His email address is marko.hofmann@unibw.de. 